\title{
Distal Urethra
}

National Cancer Institute

\section{Source}

National Cancer Institute. Distal Urethra. NCI Thesaurus. Code C115336.

The part of the urethra that is closer to the external urethral orifice. 